\title{
Novelty, historical Consciousness and the Spectacle of Interpretation
}

\author{
Graves, Nelson P, Ph.D \\ Department of Fine and Applied ArtsIgnatius Ajuru University of EducationRumuolumeni, Port Harcourt
}

\begin{abstract}
Reflecting on the seminal theme of Biography as a provisional means of accessing artistic substance, this study dares a reading of the metamorphosis of the artistry of the Dakorois artists Victor Ehikhamenor and Youseff Limoud. Utilising an empirical analysis, principal art works of these masters are examined. However, a hermeneutic investigation is engaged to aid an unraveling of the tooling mechanisms and the art making traditions that the artists deployed in their engagement with the natural synthesis cognomen in affecting the postmodernist paradigm. The works of Victor Ehikhamenor are discussed with a hermeneutic detailing that draws attention to the peculiarities of his artistry as emblematic in the growth and development of the ethos of the reincarnation of the past in postmodernist creativity enabled by the break from the Negritude ethos of the 1960s. However, a similar investigation revealed (I) that the artist Youseff Limoud in upholstering his artistic feats diligently sourced his devises on mimetic reinstatements of the canons of academe; but introduced consceptual schemes culled from the art forms of the Congolese artist, Body Isek Kingelez; and his Swiss/Egyptian art world, specifically inspirations from the Swiss duo, Peter Fischel and David Weiss,; while (II) Ehikhamenor toed the intellectually subtle repositioning of subject matter and picture-making devices, declaiming the prime Dakarois' narratives but implanting a language of pictorial codes that deter the dearth of symbols.
\end{abstract}

KEY WORDS: biography, provisional, metamorphosis, hermeneutic, paradigm shift, upholster, deceptive silence of stolen voices

Specific Dak'Art 2016 images offer nuanced commentaries on the disentanglement from the Dakarois modernist ideology and the dissolution of its Negritude foundations in authenticity, universalistic and emotional expressive paradigm. With picture making tooling mechanisms and the story-telling traditions commonplace in Nigeria's art world, and in re-calibrations of imageries, the diverse paintings of Victor Ehikhamenor declaim the Universalist dicta of Dakarois negritude, instead inflects the Revue Noire, and NKA inspired breakup of its 1960s paradigm. In fact, both journals, aiming at the widest possible international art world, its media and the "tourist gaze", affected discourses of cultural identity on the African art world; the framing of the African body, urban sites and the dynamics between African aesthetics and the Western outlook (Achille Mbembe, 2015). However, Youseff Limoud's works while in sync with the same spirit engage the versed, poetic and political language of the sculpture and cardboard architecture of the Congolese, Body Isek Kingelez; and the "fun cities" of Peter Fischli \& David Weiss. Tapping the debacle and ruin of the Syrian crisis as metaphor for the character of today's troubled times, Limoud adapts that sensitivity to steer a narrative (Youseff Limoud, 2016). That discourse, writes Elsa Guily (2016), raises questions of socio-political circumstances while speaking about geological facts and passages of time in a chaotic world, in constant motion. Both artists, exemplars of the cultural turn and the fever of independence (Kwame Nkrumah, 1965), reflect ways of being African in singular expressions that make a distinction between Africa and Africans, between identity and nationality; between expression and politics (Simon Njami,2016). Becoming explicitly African, therefore, these artists make existential choices by grasping an assemblage of personal puzzles in the recalibration of personal expressions in language and imageries that inflect individual spiritual ties to ancestry and the actual world. It is, however, prudent to recognise that artistic vectors may not be sufficient scaffolding for the transcription of the world of sensations, usually in constant motion, and ever fleeting in their very essences. Images and representations put forth by these artists deserve attention and publicity for they reveal insightful, informative, intellectually stimulating and mentally fulfilling ways of reading contemporary art. Hence, these demand comprehensive narratives that discuss African artists' works as the overarching accessory of change that ingrained the reality of the break from the erstwhile Dakarois canon. Symbolically it is important to reflect upon the notions of power that these images inflect (Michel Foucault, 1982). This paper, therefore, attempts (I) an empirical analysis of principal art works of Victor Ehikhamenor and Youseff Limoud to reveal the picture making mechanisms the artists have engaged, and (II) a deconstruction of the art works. engaging Sigmund Freud's Psychoanalysis (1910) as grounding. 
Before the details of this essay, it is important to situate the biographies of Ehikhamenor, emphasising the parochialism of his education and background; and Limoud's liberal artistic exposure to the Canon. However, George Kubler (1962) notes that artists' lives are the magnets that bridge traditional and progressive art practices, in spite of reflecting contemporaneity. The biographies of these two artists, offer a provisional gleaning of their artistic substance (George Kubler, 6-7). Both masters are qualified individuals bestriding the new tracks of development emanating from renovations of the Negritude canon inspired by Revue Noir and Principal European sponsored exhibitions of the time, for example, the Seven Stories about Africa Exhibition. In this essay, therefore, I take the view that if the biography of artists is sufficient provisionary means of gleaning the groundings of artistic substance; then the artists' works reflect conscious masterpieces that inflect symbolic codes in particular patterns of narratives, metaphors, storytelling mechanisms and choices of artistic content. In spite of being inheritors of the modernist tendencies dye-stamped on world art in the 1960s; these works reflect departures that signal the collapse of the Dakarois modernist ideology and the dissolution of its foundations.

\section{YOUSEFF LIMOUD}

An Egyptian born in Giza (of dual nationality, Egyptian\&Swiss) and 1987 graduate of the College of Fine Art, Helwan University, Cairo; Limoud is also Swiss and German educated. Major works are in Painting and Installation. A keen writer on Art and Criticism, celebrated in Arabic newspapers and magazines. Youseff lives in Bassel and Cairo.

\section{VICTOR EHIKHAMENOR}

A child of artists and artisans: grandmother, a cloth weaver; mother a local artist, a goldsmith maternal grandfather and a photographer uncle; Victor was poised for a career in the visual arts. In fact, Ekhikamenor grew up in a large extended family with grandparents, oral storytelling; the chronicle, rhythm and beat of Esan life; with Esanland art and architecture, especially wall paintings; installation and performance arts of UdomiUwessan, was a commonplace spectacle. A graduate of English (1991) Ambrose Ali University, Ekpoma, Edo State; Victor proceeded to the USA for further studies. He obtained MFA (Creative Writing) and M Sc, Technology degrees. keen enthusiasm and study of Western Art books formatted his visual education (Liz Bolshaw, 2016). In works as diverse as I Hope You Remember, a traditional textile women's headscarf is created as a homage to his mother; The Struggle for Big Afro Mama, a political work inflecting women's exploitation and the plunder of African natural resources with its slanted political themes, and The Prayer Room, suffused with religious symbolisms; Ehikhamenor demonstrates how memory and its associated themes of magic and realism are central to his works. In spite of folkloric themes, village traditional rituals, Christian Catholic world views are inflected in his visual thinking (2016).

\section{ART WORKS}

Maqam (Fig. 2)

Maqam, a palimpsest of metonymic objects rid of western perspectives overwhelms and psychologically absorbs the viewer; is sited in a three dimensional space. This Palais de Justice, Dakar, main hall is site specific, ephemeral and impermanent! The immediate impact of this image is that of engulfment. The viewer is automatically not only faced with a seemed landscape scenario, but is submerged. Engaging the viewers eyes, the feel of engrossment, writes Claire Bishop (2005) is an encounter suggestive of reading a book, watching a movie, or even dreaming. This recitation of total psychological absorption by the art work is a unique quality of this installation. Discarded items of courtroom furniture: for example the Witness stand, are prominently located in the ensemble of the empty Judges' wooden deck complex, with trimmings from the old courtroom. This artwork is reminiscent of the cardboard architectures of the Congolese sculptor Body Isek Kingelez and the "fun cities" of Peter Fischli \& David Weiss. Tapping the debacle and ruin of the Syrian crisis as metaphor for the character of today's troubled times, Limoud adapts that sensitivity to steer a narrative (Youseff Limoud, 2016). That narrative, writes Elsa Guily (2016), raises questions of socio-political circumstances while speaking about geological facts and passages of time in a chaotic world in constant motion. The installation examines the potential of the creative imagination with only elements of nature such as earth, sand, wood, stones, metal, light; and discard as raw material to create a wide field of an alternative topography. In fact, suggestive of a dream state scenario, primarily in visuals (dreams reflect a thinking process fused with music played from Alexis Peskine's Raft of the Medusa video and art installation in sensory vividness more akin to conscious perception than to memory, dreams "construct a situation" that we "experience". The basic character of this composite structure makes sense only if taken together with its constituent parts analysed (as metonymic parts of a narrative) via individual associative meanings that the entire art work be understood. A lengthy interview with Elsa Guily (2016) revealed that Maqam deliberately serene, recalling a calm after a storm; is not a Marquette. In fact, the word represents a poetic reflection utilising discarded materials full of aesthetic qualities. It is a direct response to the curatorial concept of a reincarnation undergirded in the poem, 
The City in the Blue Daylight. The very use of the metaphor compliments the use of the abandoned courtroom as an epitome of nostalgia. The appropriateness of the dream as an analogy for this installation is borne out of the total effect of the art work on the individual. The engineering of the art work is the cranking up of the wheel of association, both cultural, everyday analogies; and personal memories. In a suggestive landscape, Limoud employs objects from the site of a former courtroom such as items of furniture, significantly the Witness stand and railings with highly polished arm rests; and pieces of discarded interior furnishing trimmings, such as wall tilling and shelving units. In combination building construction objects, such as infrastructure metal rods and pile timber; lumber from down town Dakar Construction sites are prominently included. A foreground miniature landscape with suggestive imaginary metropolitan features: gobbled promenades and modern high rise consortiums and condominiums reflect a modern European inspired city. A well ordered landscaped with urban open spaces is symbolically included. However, naked infrastructure building rods poking skywards; with shells of uncompleted structures, waste timber planks and construction rubble lying loose; workmen's tools and canteen equipage, and by the melee of discarded objects reflecting imprints of their former uses reflect the reality of weird abandonment. Desolation is further echoed. Metaphorically, therefore, Limoud forces his audience to look and read the monumental picture freely from the varied vistas before them. Calling forth the sensory immediacy of conscious perception, a composite structure and the illumination of meaning through free association; correspond to a model of viewing experience found in the "total installation". The viewer is supposed to project himself/herself, get immersed in this massive scene. This scene demands a deployment of creative free association of the objects in playful display in front of them. Taking the assemblage one by one and read "symbolically" as metonymic parts of a narrative. Appropriating dream as an analogy bears out how the installation on the viewer. Maqam, a kaleidoscope of innumerable "art works", forces cultural and personally specific associations on the beholder. Youseff invites the viewers to fantasise on the complex psychological interiority of the artwork. The viewer is drawn to reminiscence and reflections on the familiar past. Youseff draws attention to his own way of expressing the central thinking of the pan-African exhibition kernelled on the general theme of reinvention via protean creativity. Limoud states, "An artist has to be a visionary. Someone who sees things without looking but senses their materiality" Utilising that metaphor, therefore, he makes critical statements on the state of the city of Dakar. He sees ingenious survival in spite of the obvious collapse of ideals all round it. Collage and the use of re-cycle able materials are his grounds for analysis. Keen on reflecting Njami's metaphor, the artist adapts the materiality of the city. Hence, his appropriation of the space of the Palais de Justice to create the illusion of dreamlike imaginary walk through a real city is most apt. But this art work simply shows dust and discards, detritus of a once prosperous condition of life! "Made of dust and return to dust" as metaphor underscores the imperative for the reengagement with commonplace things in Art's search and disclosure of the "invisible genesis" of things to come (M. Merleau-Ponty, 1945). Indeed, in the spirit of Algiers 1969 and Dakar, Maquam addresses notions of "becoming" truly endogenous in ideas and foisting new directions from the grounds of Africa. In protean language, "It is, henceforth, a matter not only of revalorizing cultures but also bringing them to life on a daily basis (L. Sedar Senghor, 1995). In all, this Installation with its religious underpinnings represents the place for spiritual refreshment, rejuvenation and the rooting for the spiritual ethos that would reinvent the Dakarois. Borrowing themes from the Congolese sculptor Body Isek Kingelez and the 1970s Swiss duo Fischle and Weiss, Limoud crossed the unusual materials and processes of post-minimalism with a squirrelly spirit of inquiry via fanciful metaphysical experiments and arrived at his own stylistic blend of architectural philosophy. These are spanners in the works of art, truthseeking phenomenology in pursuit of what may be described as "the pleasure of misuse" looking for success in failure, asking unexpected questions, and of arriving at waggish answers like an Illuminati alchemist of modern life. Debunking strapped and spooked art-school strictures and what's "permissible", Limoud reflects the ultraself-conscious, creativity of the 1990s. Youseff lets art unspool. No part of the Installation is any more or less important than any other part. The entropic work as a whole perfectly is paradigmatic of the "dream scene .characterised by both absorption and physical immersion, the viewer in encounter is placed in the middle as a protagonist. Capable of triggering fantasies, individual memories and cultural associations" in the viewer's mind, this symbolically suffused dream scene, provides a poignant model of comparison for our experiences of the work. The use of found materials bears the indexical traces of previous use. This acts as a further trigger for reflection and free association. It is, therefore similar to grand paintings, reading and cinema. The rather subjectivity of interpretations, and Limoud's insistence on fresh thinking; plural and the provision of fragmented vistas affirms the place of a psychological interpretation. Deconstructions of this unruly design suggest the design principle of the ready-made, or the use of found footage in the design of new objects. Surrealist artist, Marcel Duchamp( ) presented to the world the first exhibit of the ready-made, or objet-trouve: the Urinal and Bottle-rack ( ). Besides the immediate transformation of the toiletry into an art work, much later invented again by Andy Warhol with the Soap boxes (1964), Youseff Limoud's Maqam is the novelty. It is no coincidence that the doctrinaire artist begins with is the most Swiss of all: Dada. 
The Prayer Room (Fig. 3)

Victor Ehikhamenor's psychedelic work forces the attention of both visitors and social media audience. Prayer Room is made up of a loop shaped Mirror located on one wall of a rectangular shaped wall draped with canvas. Drawings and an All Over pattern rendition of iconographic motifs covering all the four walls, floor and ceiling of the interior of this rectangular space, adapted from regular commonplace parlor design in Esan-land". Victor takes his architectural idiom from the upland Edo tradition derived from Benin royal architecture. An elders' rectangular aligned meeting space "Okougheleh, is a place of solace, prayer, meditation and reflection for the folks! Here elders, usually peasant farmers and artisans find moments of reflection, a little relaxation and entertainment after a grinding day's work. Prayer Room is characterised by endless line work, shapes and hidden faces shrouded in a cover of motifs. With a giant loop shaped mirror dominating one wall of a rectangular space, inflecting trompe l'oeil affects relief sculpture on two walls. This creates the illusion of a repeat sculptural motif on all four walls. Otherwise, the entire wall surfaces of vibrant deep white wash paint are simply enveloped in a montage of abstract motifs and symbols. That illusionary white ground, reminiscent of traditional Benin shrine walls, permits the roll-off of blue Orishaic symbols and patched motifs enveloping the entire surface. These symbols and motifs are alluded to as visual alphabets and codes by the artist (Dave Mann, 2016). Distinctive in this florescent Light lit room is the enforced gaze effect created by the All Over pattern repeats on entire interior surfaces. Capturing humanity, evanescence and transience within the picture, Ehikhamenor enacts his story incorporating traditional African motifs and religious cosmological iconography into a contemporary artistic medium. This artwork celebrates no other enigma than the visibility of a unique Esan way of "thinking". The surfeit of imagery is native to folklore and iconography of the Esan people. It enunciates a new way of seeing, making visible metaphysical significance folk truth! Merleau-Ponty asserts that this is distinctive for in 'the entire history of painting in the modern period', has metaphysical significance, because modern painting struggles to detach itself from perspectival illusionism and to acquire its own dimension" (Merleau-Ponty,1993). It makes sense to recognise in Prayer Room Victor's portrayal of his spectacle of depth in his own "global locality". In language reminiscent of the disentanglement from the Negritude hybidisation narrative, he dares to engage the iconography of his motherland unraveling thusly, its immanent visibility, directly witnessed from within, as a hinge for explicating the subjective aesthetics, thinking and the narration of reality. Hence, it is the artists daring "becoming at home" in his own visibility. This is the new language that opens up avenues for reading and communicating his unique image, and other different voices and imageries outside the paradigms of negritude arts. This gives the painter his place in the reality of the post Dakarois world. This is the secret of representation for this artist. Merleau-Ponty (1963:128) alludes to this phenomenon as "this secret and feverish genesis of things in our body". Ehikhamenor engages nonobjective painting to affect a life situation which resists crystallization into the forms of distinct discernible features. Let us dare to look at this velvety shroud in its deep blue cool speechlessness and reflect on what it says in its mute eloquence. Declaiming all mimetic representation, a garland of abstract motifs and symbols invoke absolute music to the eyes of initiates. Only the relation of flat shapes and colour, without reference to specific objects, remain as a kind of visual music which addresses us in the speechlessness of this modernistic tableau. In spite of his canonic art education, Victor dadiastically takes inspiration from the ontology of his native Esan roots. Culling its Traditional architecture and decorative tableau specifically the "Okougheleh", elders' communal meeting room is central to all his works (Victor Ehikhamenor, 2016). It is apt to look at that ground for the poetic ontology of Prayer Room. He dares a synchronisation, crossing borders via confluences of two traditions (the Esan for shapes and forms, and the western by way of pigments). Through critical negotiations, this is the vernacular base, to borrow a word from Stuart Hall (2008) that inspires his forms and shapes. Unconscious factors, compulsive drives, and interests not only determine our behavior, but our perception as well. Claiming that Esan poetic literature is the religion of his art; Victor engages inveterate repeats of imageries drawn from that cosmology. In adaptive human play, therefore, his work is expressive of that heartfelt polemic and its rhetoric's. Resplendent in endless line work, effecting shapes and shrouded in a cover of motifs, with the canvass molded figures as the only tangible imagery; Ehikhamenor's (henceforth, VE/ VE's) poetically couched narrative recreates Okougheleh as the essence of this spectacle. In resplendent blue and white (reminiscent of white chalkiness of Benin shrines and rituals) Ehikhamenor expresses fundamental realities of cool aesthetics. The "cool" is fundamental to his native Edo and the Black Atlantic. It is expressive of the ideals of balance and control; the cool of creative manners, full of motion and brilliance" and the cool of social responsibility. That cool resonates in "shared traits" in West African ritual dress code. In fact, it is evident in the Americas with slaves who wove it into a rich and dynamic Creole civilization (R. Farris Thompson, 1973). Engaging "line" as the fundamental essence of art making, the manual and the poetic is clearly determined by the kind of knowledge involved. One hermeneutic view draws attention to the use of poetry as a point of departure in a quest to read this art work. Alluding to the words poesis and poites, Hans-George Gadamer(1988) emphahsises the specific sense in which both words reflect the process of creation and the creator. That double meaning makes a semantic connection between a specific kind of making and producing 
and other forms of the same activity. That draws attention to the imperative of viewing poetry as the fundamental grounding on which creation and creativity belong. This is the thrust of VE's work. In fact, knowledge and faculty direct the productive activity of both the craftsman and the poet; whose activity is directed towards the work and its consequent use. The work of art's public functionality is embedded in the context of life, where it occupies a position of its own in the processes of religious worship, in recitation/ theatrical performance; and even decoration and embellishment. In an African setting oral tradition is the mainstay of discourse. The word enjoys unlimited power and ideal perfection in poetic evocation that depends on reproduction via dramatic play, recitation and reading. Hence, there is no other respect in which a linguistic work of art has to be for anything else. The oral traditions that enact the narratives that ground VE's works are properly speaking "made". In his Dadaistic resort to lines and the iconographical decorative tableau and embellishments in The Prayer Room, the pleasure of persons who recognise what is represented, show the real significance of imitative representation. There is no question of judging the degree of accuracy with which the representations approach original Esan iconography. This creation like every representation, finds its genuine fulfillment in the reality that what it represents is recognised as categorically there. This is the essential purpose of esoteric character of cults. Knowledge means recognition. Mimesis, says Gadamer (1998) is a representation in which we know and have in view of the essential content of what is represented.In spite of his canonic background, VE recalibrates memory of the tangible past in ephemera, engaging colonial materiality but applying an "aesthetic of the cool" taken from his Esan roots, while circumventing western aesthetics. He found, instead, a new way of reinterpretation and discourse of individual experience in Okougheleh. With esoteric cultic suggestiveness, the art represents a transformation of the old Elder's Meeting Room in novelle concepts, shapes and volumes. The aesthetic coolness of this work is an absorbing spectacle, resplendently engaging mimesis, poetic lyricisms and share coolness to affect a gaze. In an eternal return to same, Victor restores the essence and values of the past, while validating their timelessness.In nouvelle shapes and volumes reminiscent of the playfulness of art (Gadamer, 1986:123-6) Ehikhamenor and Limoud seemed "got rid of everything that smacks of journalism, worms, everything nice and right, blinkered, moralistic, Europeanized, enervated by saying dada like the Zurich artists 100 years ago." (Karen Kedmey, 2016). In concert with the kin-folk consciousness of the erstwhile cultural policies of Senghor, the artists utilised endogenous cosmological imageries, manmade factory products: pots, pans, plastic bottles, even wires and threads; to create artworks. These creations, distinguished by their characteristic transience, simply played out the texts of the fiesta. Epitomising "recycling", these images are directed to the literati, the Élan vital; people with a certain level of intellection and education, ready to read the images that are cast in front of them. Reflecting the effects of the Revue Noir and NKA proposals, these seminal works focused their energies on the imperative of an African nationalistic consciousness grounded on notions of independence and freedom, first and foremost as a result of independence. Sequel to that ethos, it was the responsibility of artists from the new nations to vent unique ways of expression in all the disciplines of the imagination (music, dance, theatre and literature; fashion and aesthetics) especially the visual arts. Thus, breaking away from the Universalist dicta of the Dakorois 1960s; but foisting a new reconstructive "seeing process" with ingenuity in sync with a synthesis (Maurice Merleau-Ponty, 1945). With their varied portmanteaus, the artists bestride the tracks of development in the hibridisation of art for the purposes of a "seeing process" in a postmodernist paradigm. That seeing process took on a dual toll (i) a retooling process in the present and a resurgence of own oeuvre. The new artist had to, first and foremost, break from the Negritude hypnosis (for that cognomen had served its purpose of hybridisation for the Dakarois 1960s); but move beyond the present in an attempt to re-see in the nodes of his culture and aesthetics. Thusly, the artist must dare a reconciliation between so called African identity and a certain idea of worldliness, if not outright cosmopolitanism in language of colour and native imaginary, as a mastery of that ontological reality. Hence moving forward the artist with line/lines, colour, voices and iconography that eludes "globalisation and uniformisation" re-appropriates the moment of consciousness, counters his education and training; but engage in a production of own vision.

In a graphic retort to the mythical "eternal return of the same", in recognisition of the structures of polytemporal analogy (Bruno Latour,1993) I engage the metaphor and legend of the "Python's all seeing Eye" E.J. Alagoa (1997) to kernel the discourse of the new imaginary. Insisting on the discovery of their own way of "seeing", artists must give meaning to it in their work through the realisation of this new gaze. This is the penumbra, the fringe that the new artist resorts to for illumination and rootedness. These artists are beset, therefore, in deconstructing a past and daring to invent a future in a present time that is synced to perpetual renewal like the symbolic python movement. That demanded a reinvention of self, but fusing a new language that reflects that aspiration in a lexicon logy that would be readable by all, irrespective of history and milieu. Simon Njami (2016) writes, myths and legends, even the esoteric realms of belief systems of thought must be demystified so as to become vehicles of self expression. It is the burden of the creative artist to unravel the codes in which tradition was set forth. Indeed, the purpose of the artist in the new dispensation is to set the schema that would be readily visible and legible to everyone. 
IV CONCLUSION

Consciously exhibitions express discursive stances, expressing "reality" from a particular standpoint, reflective of particular interests. Dak'Art 2016 presents an enabling, comprehensive and encompassing narrative that connects the cognomen as a subtext of the larger discourses of attempts by African artists to explore personal quests centered on self with notions of identity shifts. This Exhibition makes visible for all time the emancipation of the autonomous African voice. Hence, debunking notions of African unity in terms that firstly it confirms and pleads virtuality; Dak'Art2016 hard-nosedly projected the singularity of each artist's recalibration of their Africanite from the vantage point and sensibilities of background codes and taste. That new art form, thusly, reflects departures from the Negritude consciousness; but furthers the avant-gardes' of the 1990s and a realisation of her ethos in the international art world. Reveling as a sub-text of the larger discourses of Paris inspired modernisms, the mélange of "complexifications", constituted a vehicle for the smuggling in of a convergence point of Euro-Africa postmodernism. On that scaffolding an international message of Conservation via creative utilisation of commonplace objects for art making was foisted.

Political independence demanded that the artist break from the Universalist Negritude canon was inevitable. The new dispensation equally meant, amongst other things, the unlearning of the habit of looking at oneself as an immutable schema defined by the gaze of the Other. It is the burden of the liberated artist to break from that outlook; make existential choices as to take possession of his own gaze and give it meaning. This was equivalent to giving meaning to oneself. In the eminence of decolonization and emancipation, it was the burden of the artist to construct a new "way of seeing" in his work. This was fundamental to the freedom of independence. A shift in the ethos of the artist effected a Foucaultian (Michel Foucault,1987)new ethos for the visual artist. Consequently, the artist had to come out of a long night of blindness, gradually opening to the world and presenting the magic of this consciousness. The new artist expresses an individualist view point to the world. Understanding the visual artist means being able to decipher the original language in which each artists' narrative addresses the world. Communicating to Africa and the world the artist attempts to express the "puzzles" that constitute narratives in language, "one of the instruments that transform the chaotic world of sensations into a world of objects and representations" (Henri Delacroix, 2016). Though these are perfect vectors for translating what cannot be said in art video, photography or video, media in which representation takes on human form; a certain inevitable loss is inherent in this exercise of translation. The work of art is an ample exegesis of the relationship between artistic creation and creative consciousness. A perfect retranscription of the world of sensations, always in motion, remains elusive in their very essence. How artists plan their artistic feats prior to execution remains silent on the art historical coastline. Novelty, historical Consciousness and the Spectacle of Interpretation attempted a reading of how in narratives, typical of storytelling, the artists express the texts of their inspiration in language that expressively declaims the Universalist illusions of the Dakarois art world. Instead, these artists' express visions in metaphors and idioms that acclaim personal content and styles that are readily readable to the elan vital and persons with an education and undergirded by awareness that Paulo Friere (1964) speaks of, education for national consciousness and awareness, concienziiciento! Declaiming the Dakarois synthesis, they instead present an expressive image of renascent African philosophy of being emphatic on embodied essences rather than on the avowed abstraction of a world expressed as an equation. The Christian separation of being and nature is the touchstone of this opportunity. The artists dared to interpret the essence of their selves, their ontology, from the stand point of an individual expression not the blanket cladding of the Negritude tradition. It is a decentering! These artists, thusly, achieved a "seeing power" (Maurice Merleau-Ponty, 1984), in fact, in modern parlance "born again". This is a truly mystical experience. Thusly, a split, declaiming Dakarois avant-garde is the kernel of works of the contemporary artists presented here. That demystification of the gaze of the colonial should be perceived in two ways, firstly a break from the defined view of the Other, and the resonant spiritual perception of ones' own way, to judge and construct own opinion. However, that break and the new seeing process is best alluded to as a process of emergent renewal after a long night of darkness and the magic of a discovery of real self! It is the power of the image at enthroning contemporarneity! Independence and the whirl wind of globalisation enshrined variability and individualisation of roles instead of the collectivism that Universalist stance instituted. Rather than define themselves as groups wherein the same dynamic world at work, Africans led by artists entered a phase leading them to explore personal quests centered on self. Deconstructing perceptions and preconceived notions of unity, therefore, notions of identity, revision, nomadism, cross-culturalism became the leitmotif in an endogenous definition of self (Njami, 2012). Artists like Limoud and Ekihimanor, for example, found new spaces for individual expressions. Guided by the revolutionary literature of the 90 's, principally Revue Noire, an instrumentality of growth, development and change in the drive towards a redefinition of the subject of African art; the artist found ready armory for breaking new ground. These textual realities were, however, translated to subsequent biennales in which these manifestoes were recited in artistic creations: Dakar, Bamako, and Johannesburg, et cetera. 
Grounded on the word "gaze", therefore, Maurice Merleau-Ponty (1945) in terms reminiscent of E.J. Alagoa's "The Pythons Eye" (1997) points out that nothing is new; only an "eternal return of the same". For artists take their texts from backgrounds that are entrenched in their histories as pits of real inspiration. Validating E.J. Alagoa's "The Python's Eye" Nietzsche further informs that once the artist captures that past in present imagery, it becomes automatically frozen in time. The future, therefore, would reflect an extrapolation of the lived instant, a projection that would hold only through the strength of the artists' personal vision, in the light shed by the gaze. This is the real essence of the artistic works. Little wonder, that the artists delve into the domain of metaphor and legend. This is the raison d'etre for the artistic imaginary and its resort to the ephemeral in the works of their contemporaneity. This postmodernist stance confirmed the collapse of the Universalist ideology of the 1960s; and the dissolution of modernisms foundations in authenticity. Artistic production became the threshold for the expression of individuality of both national and individual personality. The waning years of the $20^{\text {th }}$ century witnessed the decolonization and the emancipation of nations'; and the collapse of the West's monopoly on the faculty of seeing (on the power to describe and define the world according to a hegemonic viewpoint. Procrustean impositions: photographs of the indigenous inhabitants of the South Sahara or orientalist photography in the North formed part of a conscious desire to reduce all different humanity to a set of comfortable clichés which harped on otherness and eroticism. Gaining mastery of our own image translates comfortably to mean introducing our individual version of ourselves, in accordance with our cultural codes and aesthetics. It means re-appropriating of the measure of time, which according to MerleauPonty (1945) but reminiscent of the seminal thesis The Python's eye: The Past in the Living Present (Alagoa,1997); asserts that the past remains the same, because the past is a former future and a recent present, the present is an impending past and a recent future, and the future is even a past to come; that is because each dimension of time is treated or viewed as something other than itself; that is , ultimately, because in the heart of time there is a gaze. Distinguished by the reality of intangibility, reincarnating a living collective memory, with its rituals and sacred experiences of commencements, however, contemporary art and its artists face the reality of the credibility of the reinterpretations of endogenous history. That is the task for future work: keeping history intact in the spate of reinterpretation of oral history and tradition in their continuous re-workings to suit the codes of artists. To give meaning to individual works, a deconstruction of the past and inventing a future is a hard nut to crack! However, Simon Njami (2016) draws attention to the ethos validated by Nietzsche, Alagoa et al, emphasising every approach as fragmentary, illustrating that we are simply part and parcel of the puzzle whose general contours escape us to the very end. The individual artists in nouvelle imaginaries borrowed from both extant histories, even fancy imageries and vignettes culled directly from the twentieth century artists like Body Kingelez, Peter Fischli and David Weiss. Ehikhamenor's Okougheleh, reincarnated in The Prayer Room, simply put is a metaphor that undergirds the universal truth that every art work is an incarnation of some earlier form. A common thread among the works is the seemed artistic fascination with the banalities of life, the enduring love for everyday objects as the stuff of art, while entrancing the playfulness of art with spontaneous creativity.

\section{REFERENCES}

[1] Alagoa, E.J. (1997) The Python's Eye: The Past in the Living Present”, Inaugural Lecture Series I, University of Port Harcourt.

[2] Bishop, Claire (2005) Installation Art, Tate Publishing limited, Millbank, London, pp. 15-16.

[3] Bolshaw Liz (2016) http:// www.ft.com/cms/0/a3544b.56-ce34-11e4-86fc-00144feab7de.h...

[4] Bruno Latour (1993) We have Never Been Modern, Trans. Catherine Porter, Cambridge :Harvard University Press, pp. 74-76.

[5] Freud, Sigmud (1900) The Interpretation of Dreams.

[6] Guily, Elsa (2016) http://www.contemporaryand.com/exhibition/dakart-2016-the-city-in-the-bluedaylight/

[7] Kubler, George (1962) The Shape of Time, Yale Uni-Press, New Haven \& London, p. 6.

[8] Mbembe, A (2015) The Value of Africa's aesthetics, in Arts and Culture/13 http://mg.co.za/article/201505-14-the-value-of-africa-aesthetics\#.V...

[9] Moxey, Keith (1998) Art History's Hegelian unconscious, in The Subjects of Art History, Historical Objects in Contemporary Perspective by Mark Cheetham, Michael Ann Holly \& Keith Moxey, p. 27.

[10] Rabinow, Paul (1982) ed. FOUCAULT Reader, Penguin Books, London, p. 76-100.

[11] Merleau-Ponty, M (1945) Phenomenology of Perception, Trans. Colin Smith, London: Routledge \& Keagan Paul; New York: The Humanities Press, 162; 442.

[12] Merleau-Ponty, M (1993) Eye and Mind, in The Marleau-Ponty Aesthetics Reader, Philosophy and Painting, ed. Galen A. Johnson (Evanston: NorthWestern University Press. p. 126.

[13] Merleau-Ponty, M (1964) Eye and Spirit http://pg2009.files.wordpress.com>eye.... 
[14] Njami Simon (2016) Against the Universalist Illusion, Fundation Sindika...http://www.fundationsindikadkolo.com/encontre-illusion-universaiste

[15] Nkrumah, Kwame ((1965) Neo-colonialism, The Last Stages of Imperialism, Heinemann Press \& Publishers, London.

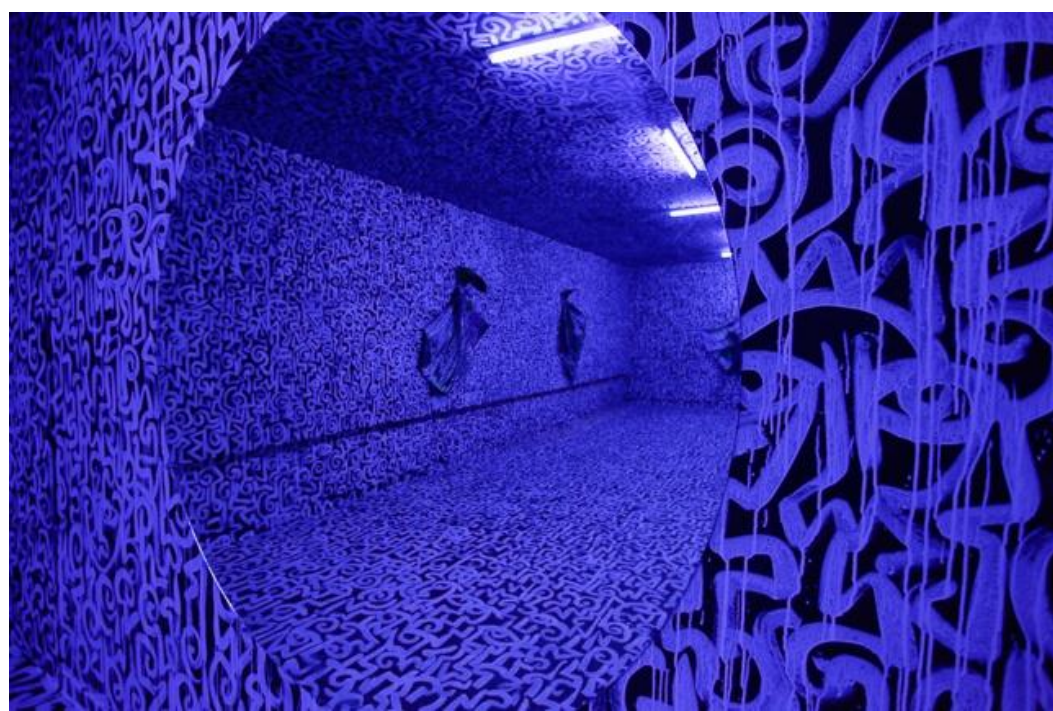

Fig. 1. Victor Ehikhamenor, The Prayer Room, 2016, Mixed media Installation, Dak'Art 2016 international exhibition, Installation view, Palais de Justice (C) C\&

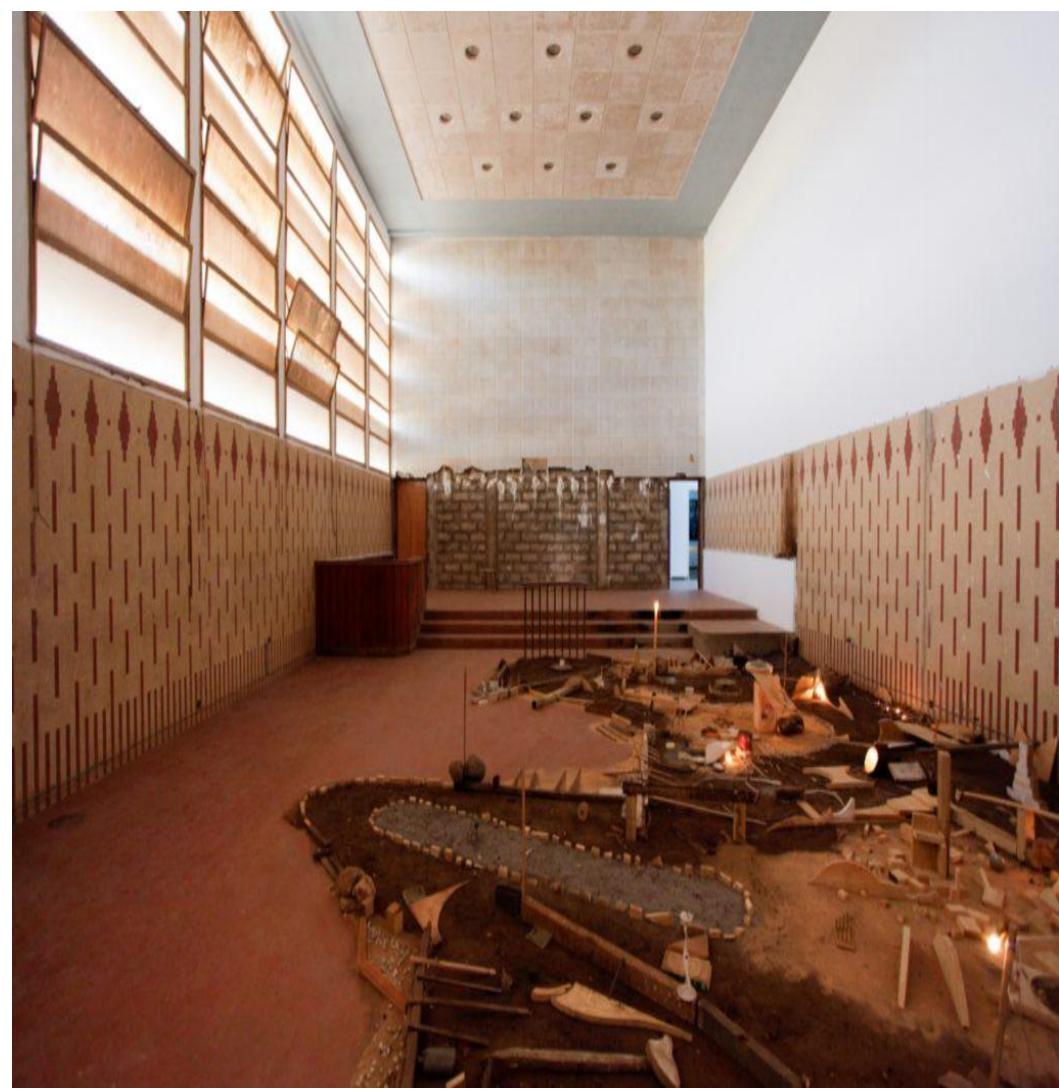

Fig. 2. Youssef Limoud, Maqam, 2016. Mixed-media Installation. Dak’Art 2016, international exhibition, Installation view, Palais de Justice $@$ C \& 